\section{A New Effective, User-friendly Bacterial Vaginosis Treatment: A Randomized Multicenter Open-label Parallel-group Two-part Study with a Novel Sustained-release Pessary Containing Oligomeric Lactic Acid}

\section{Margareta Fredstorp ${ }^{1}$, Aino Fianu Jonasson ${ }^{2}$, Anders Barth ${ }^{3}$ and Jeanette Robertsson ${ }^{4 *}$}

${ }^{1}$ Sophiakliniken, Stora Söderg 8C, Lund 22223, Sweden

${ }^{2}$ Department of Clinical Science, Karolinska University Hospital Huddinge, Unit of Obstetrics and Gynaecology, Karolinska Institute - Research Unit for Women, Sweden

${ }^{3}$ Partus Clinic for Women, Södra vägen 2, Göteborg, Sweden

${ }^{4}$ Pharmaceutical Development and Quality, PULS AB, Kullagatan, Helsingborg, Sweden

\begin{abstract}
Introduction: Bacterial Vaginosis (BV) is an imbalance in the naturally occurring vaginal bacterial flora resulting in lack of vaginal acidity, inhibition of the normal lactobacilli growth and overgrowth by mixed anaerobic bacterial flora including Gardnerella vaginalis. The prevalence of BV is estimated at approximately $15-30 \%$ among fertile women and frequent recurrences several times a year are common. BV has a negative effect on many women's lives, in particular due to the odorous vaginal discharge. First line treatment with antibiotics is associated with adverse events, high relapse rates, and an emerging risk of bacterial drug resistance development. New antibiotic-free treatments with high efficacy and less frequent administration in combination with high patient acceptance are needed.
\end{abstract}

*Corresponding author: Jeanette Robertsson, Pharmaceutical Development and Quality, PULS AB, Kullagatan 8, Helsingborg SE-75220, Sweden, Tel: +46 708637419; E-mail: jeanette.robertsson@pulsinvest.se

Citation: Fredstorp M, Jonasson AF, Barth A, Robertsson J (2015) A New Effective, User-friendly Bacterial Vaginosis Treatment: A Randomized Multicenter Open-label Parallel-group Two-part Study with a Novel Sustained-release Pessary Containing Oligomeric Lactic Acid. J Infect Non Infect Dis 1: 006.

Received: May 07, 2015; Accepted: August 08, 2015; Published: August 23 2015
The aim of the present study was to investigate a new sustained release treatment, an Oligomeric Lactic Acid (OMLA) pessary in patients with confirmed $\mathrm{BV}$, and to evaluate $\mathrm{BV}$ clearance, $\mathrm{pH}$ decrease, adverse events, and patient treatment satisfaction.

Methods: The study was a randomized parallel-group open-label two-part study at ten gynecological clinics. Part A: A two-week proof-of-concept evaluation, and Part B: A one-week efficacy evaluation. In Parts $A$ and $B$, the OMLA pessary was administrated either Once (OW) or Twice (TW) a week and in Part B was also compared to an untreated Control Group (CG). Non-pregnant fertile women with confirmed BV could participate. The main outcome measures were Amsel's criteria to confirm BV, vaginal $\mathrm{pH}$, adverse events, and patient treatment satisfaction.

Results: Part A $(n=21)$ showed high safety and treatment efficacy already after one week. In the pooled treatment group, the one week BV clearance ratio was 19/20 (95\%). In Part B $(n=105)$ the one week BV clearance ratios were $70.6 \%$ in the OW group ( $p<0.001$ vs. CG), $80.0 \%$ in the TW group ( $p<0.001$ vs. CG), and $10.0 \%$ in the CG. Pooled data from Parts A and B showed a one week BV clearance of $78 \%$ in each treatment group. The vaginal $\mathrm{pH}$ decreased $(p<0.05)$ in both treatment groups. The results demonstrated high patient treatment satisfaction. Most adverse events were mild and of short duration.

Conclusion: The novel OMLA pessary showed a BV treatment efficacy of $78 \%$ after one week of single-dose administration. Along with a good safety profile, user-friendliness, and no risk of bacterial antibiotic resistance development, this represents a significant improvement in BV treatment.

Keywords: Bacterial Vaginosis (BV); Lactic acid; Odorous vaginal discharge; Oligomeric lactic acid; $\mathrm{pH}$ modifier

\section{Abbreviations}

$\begin{array}{lll}\text { ADE } & : & \text { Adverse Drug Event } \\ \text { AE } & : & \text { Adverse Event } \\ \text { BV } & : & \text { Bacterial Vaginosis } \\ \text { CG } & : & \text { Control Group } \\ \text { FAS } & : & \text { Full Analysis Set } \\ \text { ICH } & : & \text { International Conference on Harmonization } \\ \text { OMLA } & : & \text { Oligomeric Lactic Acid } \\ \text { OTC } & : & \text { Over the Counter } \\ \text { OW } & : & \text { Once a Week } \\ \text { PP } & : & \text { Per Protocol analysis } \\ \text { SAE } & : & \text { Serious Adverse Event } \\ \text { TW } & : & \text { Twice a Week }\end{array}$

\section{Introduction}

Bacterial Vaginosis (BV) is an imbalance in the naturally occurring vaginal bacterial flora resulting in an overgrowth by mixed anaerobic bacterial flora including Gardnerella vaginalis, Prevotella, Bacteriodes species, Peptostreptococcus, Mobiluncus, genital Mycoplasma hominis and Ureaplasma species [1-3]. Simultaneously, an increase of the vaginal $\mathrm{pH}$ above 4.5 leads to a decline in Lactobacilli species and lactobacilli-associated antimicrobial activity $[4,5]$.

The most pronounced clinical symptom in BV is the thin white or gray discharge with an offensive or fishy odor caused by an increased 
concentration of at least seven amines which are presumably produced by bacterial decarboxylases and several volatile and non-volatile organic acid metabolites of anaerobic bacteria $[1,2]$. Gardnerella vaginalis adherent to squamous epithelial cells produces pathognomonic clue cells, which together with elevated vaginal $\mathrm{pH}$ and the odorous discharge constitute the hallmark of BV diagnosis [6]. Diagnosis relies on standardized clinical criteria according to Amsel or on scoring bacterial cell morphotypes on a Gram stained vaginal smear according to Nugent [7-9].

$\mathrm{BV}$ is one of the most prevalent vaginal infections in women of reproductive age and affects approximately $15-30 \%$ in developed countries $[10,11]$. The prevalence figures vary greatly between various ethnic groups and geographical areas. Figures can be as high as 50\% in certain regions of Africa and China [12].

BV affects many women's lives in a negative manner, not only due to the odorous vaginal discharge that causes embarrassment and social isolation, but it is also associated with a wide range of medical problems [3,13-15]. In pregnancy, BV is associated with premature labor, premature rupture of membranes, and low birth weight leading to high prenatal mortality. However, it is not known what mechanism(s) causes these adverse pregnancy outcomes [3,16-19]. As $\mathrm{BV}$ is found in approximately $16 \%$ of pregnant women in industrial countries, it poses a serious problem [3,20-22]. Approximately every second woman, both pregnant and non-pregnant, is asymptomatic, thus making treatment even more cumbersome [6]. Other medical problems include the risk of gynecologic infections following surgery and an increased risk of contracting sexually transmitted diseases, including HIV [14,15,23].

Some women are easily infected and suffer from frequent recurrences several times a year, while others do not seem to be affected at all [13]. A number of sexual and social risk factors for bacterial BV have been suggested, e.g., multiple sexual partners, smoking, douching, and using an intrauterine device, whereas hormonal contraception has been associated with a decreased incidence of BV [24]. However, in a Chinese study of more than 53,000 married women, low sexual activity was identified as a risk factor of BV [25]. To date, there is no scientific evidence showing that bacterial vaginosis is a sexually transmitted disease.

Today, antibiotics such as metronidazole or clindamycin are the most common treatments for BV and, in the US, are recommended by the Center for Disease Control [26]. Recurrences affect approximately half of the women with $\mathrm{BV}$, which means that many women are treated with antibiotics several times a year [13]. The emerging global risk of developing bacterial antibiotic resistance makes BV treatment with antibiotics cumbersome [27]. Apart from relapses, antibiotic treatment often results in side effects, e.g., vaginal Candida vaginitis, which also needs to be treated $[28,29]$. Furthermore, metronidazole interacts with other drugs and alcohol and must be taken into consideration when administered orally [30]. In vitro studies have shown that clindamycin and metronidazole inhibit Lactobacillus spp. at concentrations lower than doses topically applied for the treatment of BV [31,32]. Therefore, there is an interest in developing alternative treatments for $\mathrm{BV}$, such as selective antimicrobials, probiotics, and acidification procedures that will inhibit BV pathogenic bacteria without killing healthy Lactobacillus spp [33].

Actively acidifying the vagina with naturally occurring lactic acid and at the same time promoting the growth of indigenous Lactobacillus spp. instead of introducing new species may enhance Lactobacillus spp. colonization and prevent anaerobic overgrowth. Hence, vaginal acidifying might serve as either a therapeutic or a preventive means of BV [7].

Different types of vaginal products containing lactic acid or other weak acids, e.g., ascorbic acid, for treating BV are available on the market and require daily dosing for a minimum treatment cycle of 6-7 days [34,35]. A survey of 2660 women performed in USA, UK and Germany in 2011 clearly showed that a large proportion of those with recurrent $\mathrm{BV}$ problems were not satisfied with the treatment alternatives available [13]. The survey displayed pronounced requests for non-smeary Over The Counter (OTC) products that are easy to use and do not require frequent dosing.

The investigational product in this study is being developed by Laccure $\mathrm{AB}$ (Sweden) to meet a target product profile of high efficacy after few administrations in combination with high patient acceptance. The product, based on Oligomeric Lactic Acid (OMLA), is intended for the treatment and prevention of BV. When in contact with the vaginal mucus, a mucoadhesive acidic OMLA gel is formed that adheres to the vaginal mucosa; the OMLA is gradually hydrolyzed into lactic acid and released. The OMLA content of one pessary corresponds to $700 \mathrm{mg}$ lactic acid, which is adequate for a lasting $\mathrm{pH}$ effect for up to approximately one week (Laccure regulatory dossier). The freeze-dried product, buffered to $\mathrm{pH} 3.5$, is designed to release $\geq 20 \%$ after $6 \mathrm{~h}, \geq 35 \%$ after $24 \mathrm{~h}$, and $\geq 45 \%$ after 72 $\mathrm{h}$, which mimics the three first doses of lactic acid-based products on the market (Laccure regulatory dossier).

This is the first study using an OMLA pessary on patients with confirmed BV as well as comparing two dosing schedules of the OMLA pessary and focusing on BV clearance, $\mathrm{pH}$ decrease, adverse events, and patient treatment satisfaction.

\section{Methods}

\section{Participants}

The study was performed on non-pregnant fertile women, at least 18 years of age with confirmed BV according to Amsel's criteria and whereby a minimum of three of the four criteria were fulfilled ${ }^{1}$ [8]. In order to participate, there could be no diagnosis of yeast or Trichomonas infection or any suspicion regarding other specific lower genital tract infections. Oral or vaginal antibiotics as well as $\mathrm{pH}$-modifying products were not allowed two weeks prior to and during the study. The participants did not anticipate menstruation during the course of the study and had to agree to either abstain from sexual intercourse or use a condom.

\section{Trial design}

This clinical evaluation was set up as a randomized open-label parallel-group multicenter study with a two-part adaptive design where the outcome of the first part (A) was to influence the design of the second part (B). Part A, planned as a proof of concept study, was performed at two gynecological primary care clinics and one clinical

1 - 1: Thin, white, yellow, homogeneous discharge; 2 : Clue cells on microscopy; 3 : $\mathrm{pH}$ of vaginal fluid $>4.5 ; 4$ : Release of a fishy odor when alkali $(10 \%$ Potassium Hydroxide $(\mathrm{KOH})$ solution) is added. 
research unit for women and Part B, the main study, at ten Swedish sites including the three from Part A. Patients participating in Part A were not allowed to participate in Part B. The changes in the design of Part B, due to the outcome of Part A, were made in order to increase the required number of patients, as the decision was made to keep both treatment schedules and to include an untreated control group. Due to the good treatment efficacy at one week, the decision was also made to reduce the treatment period to just one week in Part B and slightly amend the study's end points. These changes were approved by the Ethics Committee and the Regulatory Authority (Swedish Medical Products Agency) prior to implementation.

During the study planning, a double-blind study design was considered, but had to be abandoned as developing a placebo identical to the OMLA pessary was not possible. Instead, an untreated control group was added in order to study the natural progress of BV.

Study Part A compared the dosage schedules of one administration per week and two administrations per week (on day 1 and day 4 of each week) during a two-week treatment period. In Part B, involving only one week's treatment to study the immediate treatment effect, clinic visits were performed on day 1 (Visit 1), day 4 (Visit 2) and day 8 (Visit 3). In Part A, there were also visits on day 11 (Visit 4) and day 15 (Visit 5). In Part B, eligible patients were also randomized to a Control Group (CG) not receiving any treatment but still attending the same visits and having the same assessments done as the actively treated groups. Patients in the control group who still had verified BV after the first week of non-treatment were randomized a second time and offered treatment with an OMLA pessary during week 2 .

The study was performed according to Good Clinical Practice Consolidated Guidelines (1996) of the International Conference on Harmonization (ICH) E6 (R1) [36]. The study protocol was reviewed and given a favorable recommendation by an Ethics Committee and by the Regulatory Authority. Written informed consent was obtained from all participants. The trial was monitored by an independent contract research organization that also performed the data management and statistics (Norma A/S, Denmark). Two sites were audited at the sponsor's request.

\section{Objectives and outcome measures}

The primary objective of Part A was to assess the safety of the OMLA pessary. The secondary objectives were to evaluate the efficacy of the OMLA pessary by assessing the vaginal $\mathrm{pH}$, the proportion of patients with no $\mathrm{BV}$, and the proportion of patients positive for each of the Amsel's criteria.

The primary objective of Part B was to investigate the efficacy of the OMLA pessary in patients with BV. The secondary objectives were to evaluate the safety, tolerability, vaginal $\mathrm{pH}$ levels, and patient treatment satisfaction of the OMLA pessary in patients with BV.

Detailed objectives and primary outcome measures for Parts A and $B$ are shown in table 1.

\section{Randomization}

In Part A, the two treatment arms were randomized in allocation ratios $1: 1$ by using site-specific randomization lists generated by the study statistician applying SAS version 9.2, Proc Plan (SAS Institute, Cary North Carolina USA). In Part B, the three treatments were randomized in allocation ratios 1:1:1 according to a computer-generated randomization list using nQuery Advisor 7.0 (Statistical Solutions, Cork, Ireland). The treatment arms were randomized, applying block randomization with block sizes blinded to the investigators. Each site received one set of randomization code envelopes, each with information valid for only one patient, and to be opened in consecutive order.

\section{Sample size and statistical analysis}

For study Part A, no formal sample size calculation or hypothesis testing were performed. The Full Analysis Set (FAS) was used for the presentation of the results.

In Part B, the primary hypothesis, also valid for the sample size estimation, was to evaluate the proportion of treatment successes (no BV at Day 8) according to Amsel's criteria in the group treated Once a Week (OW) compared with the untreated CG [8]. The sample size estimation was based on estimated treatment success rates of $75 \%$ with the OMLA pessary and $40 \%$ for the untreated controls. At a significance level of 0.05 , a two-sided hypothesis testing and a power of $80 \%$, the patient number needed would be 31 per group. To allow for 5 patients to drop out, it was calculated that 36 patients per group were needed.

The FAS consisted entirely of randomized patients who received at least one dose of the assigned treatment and patients in the randomized CG. All collected data from the treated patients is presented here. No imputations of missing values were performed. A Per Protocol (PP) Analysis set was also defined and analyzed in Part B.

The Wilcoxon signed-rank test was applied for significance testing within groups and the Chi-square test for testing between groups.

\section{Interventions}

On the treatment days, the OMLA pessary was self-administrated (no applicator) at bedtime according to verbal and specific written instructions.

In Part A, patients were randomized to treatment with the OMLA pessary Once a Week for two weeks (OW), receiving a total of two pessaries (day 1 and day 8) or twice a week for Two Weeks (TW), receiving a total of four pessaries (day 1 , day 4 , day 8 and day 11).

In Part B, patients were randomized to treatment with one single OMLA pessary for One Week (OW), receiving a total of one pessary (day 1) or treatment with the OMLA pessary Twice a Week for one week (TW), receiving a total of two pessaries (day 1 and day 4) or randomized to the CG without any treatment during the first week. Patients in the CG who still had verified BV after the first week of non-treatment were randomized a second time and offered treatment with the OMLA pessary during week 2 , either once or twice a week for one week.

\section{Clinical assessments and collection of study data}

The clinical diagnosis and the assessments of BV during and after treatment were based on Amsel's criteria [8]. This well-known assessment method was chosen as it was considered logistically easy to use in a multicenter setting and the diagnosis could be confirmed readily and quickly by each investigator. For confirmed diagnosis of $\mathrm{BV}$, a minimum of three of the four criteria had to be present. The criterion for no BV, defined as 0-2 fulfilled Amsel's criteria, was applied as the primary treatment success criterion. Additionally, the proportion of patients who fulfilled each individual Amsel's criterion at each visit was used as treatment efficacy criteria.

For all $\mathrm{pH}$ measurements, the $\mathrm{pH}$ meter ECPH601PLUS Eutech 6, Scandinovata AB, Bromma, Sweden was used. Study personnel at 


\begin{tabular}{|c|l|}
\hline Study Part A -Primary & $\begin{array}{l}\text { - To assess the safety of the OMLA pessary administered once or twice a week in BV patients by evaluation of adverse events judged as possibly } \\
\text { related to treatment, including evaluation of findings recorded at vulvovaginal examination. }\end{array}$ \\
\hline Study Part A -Secondary & $\begin{array}{l}\text { - To evaluate the efficacy of the OMLA pessary administered once or twice a week in BV patients by assessment of the vaginal pH, the proportion } \\
\text { of patients with no BV and the proportion of patients positive for each of the Amsel's criteria. } \\
\text { Vaginal pH at the study visits in each treatment group, proportion of patients with pH } \\
\text { BV after } 1 \text { and } 2 \text { weeks of treatment in each treatment group, proportion of patients with presence of any of the individual Amsel's criteria after } 1 \\
\text { and } 2 \text { weeks of treatment in each treatment group, and treatment satisfaction according to the patient diary. }\end{array}$ \\
\hline Study Part B - Primary & $\begin{array}{l}\text { - To investigate the efficacy of the OMLA pessary in BV patients by measuring the proportion of patients with no BV according to Amsel's criteria } \\
\text { at one week in the Once a Week group (OW) compared to the untreated Control Group (CG). }\end{array}$ \\
\hline Study Part B -Secondary & $\begin{array}{l}\text { - To investigate the safety, tolerability, vaginal pH levels, and patient treatment satisfaction of the OMLA pessary in BV patients. } \\
\text { Proportion of patients with no BV according to Amsel's criteria after one week in the Twice a Week (TW) group vs. the CG, as well as in the } \\
\text { OW group vs. the TW group and pooled active treatment groups vs. CG, proportion of patients at one week (day } 8 \text { ) with presence of any of the } \\
\text { four Amsel's criteria in each treatment arm, change in vaginal pH over time (day } 4 \text { and day } 8 \text { ) compared to baseline in each study arm, patient } \\
\text { treatment satisfaction after completed treatment in each treatment arm, frequency of spontaneously reported adverse events during treatment in } \\
\text { each treatment arm, proportion of patients with any adverse findings at vulvovaginal mucosa examination, day } 8 \text { compared to baseline. }\end{array}$ \\
\hline
\end{tabular}

Table 1: Study objectives and outcome measures in Part A and Part B.

each site were educated on how and when to calibrate and use the $\mathrm{pH}$ meter and the electrode. Vaginal smears for $\mathrm{pH}$ and Amsel's criteria assessments were prepared from mucosal samples in the middle vagina and close to the orifice, respectively. No swabs were to touch the cervix as $\mathrm{pH}$ there is close to seven, which would mislead the correct vaginal $\mathrm{pH}$. Of the two $\mathrm{pH}$ samples taken, the highest value recorded was used.

Vulvovaginal mucosa examinations were performed pre- and post-treatment by the investigator in order to assess any adverse findings, e.g., vaginal redness and irritation. Treatment compliance was checked by questioning and counting the unused returned pessaries.

In Part A, patients completed a patient diary on a daily basis and registered any Adverse Events (AE). In both parts of the study, treated patients completed a questionnaire on their final visit regarding patient treatment satisfaction. They were asked to answer whether or not they agreed with several treatment related statements, e.g." "I experienced the treatment as user-friendly: easy to insert, not messy to use and comfortable" and "I find it comfortable not to dose more frequently".

\section{Results}

The results from Parts A and B are displayed separately. As the two study parts collected patients from the same population (identical eligibility criteria) and the same treatment evaluation methods were applied, the main outcome results from both study parts are also presented as pooled. Any patients withdrawn from treatment were encouraged to attend the final study visit. Available data from withdrawn patients are included in the FAS results. Demographics from the two study parts are presented in table 2 .

\begin{tabular}{|c|c|c|c|}
\hline Study Part A & Once a Week treatment (OW) & \multicolumn{2}{|c|}{ Twice a Week treatment (TW) } \\
\hline Number of patients randomized & 11 & \multicolumn{2}{|l|}{10} \\
\hline Mean age (years) & 33 & \multicolumn{2}{|l|}{29} \\
\hline Caucasian & $10 / 11$ & \multicolumn{2}{|l|}{$9 / 10$} \\
\hline $\begin{array}{l}\text { Type of contraception used: } \\
\begin{aligned} \cdot & \text { Contraceptive pills } \\
\cdot & \text { IUD (with or without hormones) } \\
\cdot & \text { Condoms } \\
\cdot & \text { Other: hormone vaginal ring }\end{aligned}\end{array}$ & $\begin{array}{l}2 / 11 \\
5 / 11 \\
0 / 11 \\
0 / 11\end{array}$ & $\begin{array}{l}3 / 10 \\
1 / 10 \\
2 / 10 \\
1 / 10\end{array}$ & \\
\hline Previous symptoms of fishy vaginal odor at least three times in the last year & $8 / 11$ & \multicolumn{2}{|l|}{ 9/10 } \\
\hline $\begin{array}{l}\text { Medically treated for fishy vaginal odor in the previous } 3 \text { years } \\
\cdot \text { - with antibiotics (oral and/or vaginal) } \\
\text { - } \text { with lactic acid (Lactal®) }\end{array}$ & $\begin{array}{l}7 / 11 \\
5 / 11 \\
5 / 11\end{array}$ & $\begin{array}{l}7 / 10 \\
3 / 10 \\
4 / 10\end{array}$ & \\
\hline Study Part B & Once a Week treatment (OW) & Twice a Week treatment (TW) & Control Group (CG) \\
\hline Mean age (years) & 32 & 30 & 32 \\
\hline Caucasian (\%) & 97 & 97 & 97 \\
\hline $\begin{array}{l}\text { Type of contraception used }(\%) \text { : } \\
\qquad \text { Contraceptive pills }\end{array}$ & 32 & 40 & 15 \\
\hline - IUD (with or without hormones) & 27 & 17 & 39 \\
\hline - Condoms & 14 & 31 & 12 \\
\hline - Other: hormone vaginal ring, s.c. hormone implant or sterilized & 11 & 17 & 12 \\
\hline Previous symptoms of fishy vaginal odor at least three times in the last year (\%) & 78 & 77 & 84 \\
\hline $\begin{array}{l}\text { Medically treated for fishy vaginal odor in the previous } 3 \text { years }(\%) \\
\cdot \text { with antibiotics (oral and/or vaginal) } \\
\left.\cdot \text { with lactic acid (Lactal }{ }^{\circledR}\right)\end{array}$ & $\begin{array}{l}62 \\
32 \\
30\end{array}$ & $\begin{array}{l}77 \\
46 \\
43\end{array}$ & $\begin{array}{l}70 \\
39 \\
45\end{array}$ \\
\hline
\end{tabular}

Table 2: Demographics in study Part A and Part B. 
Citation: Fredstorp M, Jonasson AF, Barth A, Robertsson J (2015) A New Effective, User-friendly Bacterial Vaginosis Treatment: A Randomized Multicenter Open-label Parallel-group Two-part Study with a Novel Sustained-release Pessary Containing Oligomeric Lactic Acid. J Infect Non Infect Dis 1: 006.

- Page 5 of 12 .

\begin{tabular}{|c|c|c|c|c|c|c|c|c|c|c|}
\hline \multirow[b]{2}{*}{ Study Part A } & \multicolumn{5}{|c|}{ Once a Week treatment (OW) } & \multicolumn{5}{|c|}{ Twice a Week treatment (TW) } \\
\hline & $\begin{array}{c}\text { Visit } 1 \\
\text { baseline }\end{array}$ & Visit 2 & $\begin{array}{l}\text { Visit } 3 \\
1 \text { week }\end{array}$ & Visit 4 & $\begin{array}{l}\text { Visit } 5 \\
2 \text { weeks }\end{array}$ & $\begin{array}{c}\text { Visit } 1 \\
\text { baseline }\end{array}$ & Visit 2 & $\begin{array}{l}\text { Visit } 3 \\
1 \text { week }\end{array}$ & Visit 4 & $\begin{array}{l}\text { Visit } 5 \\
2 \text { weeks }\end{array}$ \\
\hline $\begin{array}{l}\text { Proportion with no BV according } \\
\text { to Amsel } \\
\text { Exact } 95 \% \text { confidence interval (\%) }\end{array}$ & 0/11 & & $\begin{array}{c}10 / 10 \\
{[69.2: 100]}\end{array}$ & & $\begin{array}{c}8 / 10 \\
{[44.4: 97.5]}\end{array}$ & $0 / 10$ & & $\begin{array}{c}9 / 10 \\
{[55.5: 99.7]}\end{array}$ & & $\begin{array}{c}9 / 9 \\
{[66.4: 100]}\end{array}$ \\
\hline $\begin{array}{l}\text { Proportion with negative Amsel's } \\
\text { criterion -"thin, white, yellow, } \\
\text { homogeneous discharge" }\end{array}$ & 0/11 & & $10 / 10$ & & $7 / 10$ & $1 / 10$ & & $8 / 10$ & & $8 / 9$ \\
\hline $\begin{array}{l}\text { Proportion with negative Amsel's } \\
\text { criterion -"release of fishy odor } \\
\text { when alkali is added" }\end{array}$ & 0/11 & & 9/10 & & 9/10 & $1 / 10$ & & $8 / 10$ & & 9/9 \\
\hline $\begin{array}{l}\text { Proportion with negative Amsel's } \\
\text { criterion -"clue cells on micros- } \\
\text { copy" }\end{array}$ & 0/11 & & $10 / 10$ & & $8 / 10$ & $2 / 10$ & & $7 / 10$ & & 8/9 \\
\hline $\begin{array}{l}\text { Proportion with negative Amsel's } \\
\text { criterion - "pH of vaginal discharge } \\
\leq 4.5 \text { " }\end{array}$ & 0/11 & & $3 / 10$ & & $1 / 10$ & $0 / 10$ & & $3 / 10$ & & $4 / 9$ \\
\hline $\begin{array}{l}\text { Mean vaginal pH (SD) } \\
\text { Exact 95\% confidence interval } \\
\mathrm{N} \text { (missing) }\end{array}$ & \multirow[t]{2}{*}{$\begin{array}{c}5.6(1.5) \\
{[4.5: 6.6]} \\
11(0)\end{array}$} & $\begin{array}{l}4.6(0.7) \\
{[4.1: 5.1]} \\
10(1)\end{array}$ & \multirow[t]{2}{*}{$\begin{array}{c}4.8(0.7) \\
{[4.3: 5.2]} \\
10(1)\end{array}$} & $\begin{array}{l}4.4(0.5) \\
{[4.0: 4.9]} \\
8(3)\end{array}$ & \multirow[t]{2}{*}{$\begin{array}{c}5.2(1.0) \\
{[4.5: 5.9]} \\
10(1)\end{array}$} & \multirow[t]{2}{*}{$\begin{array}{c}5.3(0.4) \\
{[5.1: 5.6]} \\
10(0)\end{array}$} & $\begin{array}{l}4.6(0.6) \\
{[4.2: 5.1]} \\
9(1)\end{array}$ & \multirow{2}{*}{$\begin{array}{c}4.8(0.6) \\
{[4.4: 5.3]} \\
10(0) \\
\\
\text { NS }\end{array}$} & $\begin{array}{l}4.7(0.5) \\
{[4.3: 5.1]} \\
8(2)\end{array}$ & \multirow{2}{*}{$\begin{array}{c}4.8(0.7) \\
{[4.3: 5.4]} \\
9(1) \\
\\
\text { NS }\end{array}$} \\
\hline $\begin{array}{l}\text { Statistical comparison of mean } \\
\text { vaginal pH vs. Visit } 1 \text { (Wilcoxon } \\
\text { signed rank test) }\end{array}$ & & $p<0.05$ & & NS & & & $p<0.05$ & & NS & \\
\hline Median vaginal $\mathrm{pH}$ & 5.1 & 4.6 & 4.9 & 4.4 & 5 & 5.4 & 4.9 & 5 & 4.5 & 4.9 \\
\hline $\begin{array}{l}\text { Proportion of patients with median } \\
\text { vaginal } \mathrm{pH} \leq 4.5\end{array}$ & $0 / 11$ & $5 / 10$ & $3 / 10$ & $5 / 8$ & $1 / 10$ & $0 / 10$ & $4 / 9$ & $3 / 10$ & $5 / 8$ & $4 / 9$ \\
\hline $\begin{array}{l}\text { Proportion with a normal } \\
\text { vulvovaginal mucosa status at } \\
\text { examination }\end{array}$ & $8 / 11$ & & $8 / 10$ & & 9/10 & $4 / 10$ & & $6 / 10$ & & $7 / 9$ \\
\hline $\begin{array}{l}\text { Proportion of patients reporting } \\
\text { AEs }\end{array}$ & \multicolumn{5}{|c|}{$7 / 11$} & \multicolumn{5}{|c|}{ 9/10 } \\
\hline Total number of AEs/ADEs & \multicolumn{5}{|c|}{$11 / 9$} & \multicolumn{5}{|c|}{$26 / 12$} \\
\hline $\begin{array}{l}\text { Proportion of patients with AEs } \\
\text { that may be treatment related (not } \\
\text { confirmed) }\end{array}$ & \multicolumn{5}{|c|}{ 6/11 } & \multicolumn{5}{|c|}{$7 / 10$} \\
\hline & Major & Slight & \multicolumn{3}{|c|}{ No } & Major & Slight & \multicolumn{3}{|c|}{ No } \\
\hline $\begin{array}{l}\text { Investigator assessment of } \\
\text { improvement at final visit }\end{array}$ & $7 / 10$ & $1 / 10$ & \multicolumn{3}{|c|}{$2 / 10$} & $7 / 9$ & $2 / 9$ & \multicolumn{3}{|c|}{$0 / 9$} \\
\hline
\end{tabular}

Table 3: Baseline data and treatment outcome in study Part A.

NS = no significance $(p>0.05)$

\begin{tabular}{|c|c|c|c|c|c|c|c|c|c|}
\hline \multirow[t]{2}{*}{ Study Part B } & \multicolumn{3}{|c|}{ Once a Week treatment (OW) } & \multicolumn{3}{|c|}{ Twice a Week treatment (TW) } & \multicolumn{3}{|c|}{ Control Group (CG) } \\
\hline & $\begin{array}{l}\text { Visit } 1 \\
\text { baseline }\end{array}$ & Visit 2 & $\begin{array}{l}\text { Visit } 3 \\
1 \text { week }\end{array}$ & $\begin{array}{c}\text { Visit } 1 \\
\text { baseline }\end{array}$ & Visit 2 & $\begin{array}{l}\text { Visit } 3 \\
1 \text { week }\end{array}$ & $\begin{array}{c}\text { Visit } 1 \\
\text { baseline }\end{array}$ & Visit 2 & $\begin{array}{l}\text { Visit } 3 \\
1 \text { week }\end{array}$ \\
\hline $\begin{array}{l}\text { Proportion(\%) with no BV according to Amsel } \\
\text { Exact } 95 \% \text { confidence interval (\%); }\end{array}$ & 0 & & $\begin{array}{c}70.6 \\
{[52.5: 84.9]} \\
p<0.001^{*}\end{array}$ & 0 & & $\begin{array}{c}80 \\
{[63.1: 91.6]} \\
p<0.001^{*}\end{array}$ & 0 & & $\begin{array}{c}10 \\
{[2.1: 26.5]}\end{array}$ \\
\hline $\begin{array}{l}\text { Proportion (\%) with negative Amsel's } \\
\text { criterion - } \\
\text { "thin, white, yellow, homogeneous discharge" }\end{array}$ & 5.4 & & $\begin{array}{c}58.8 \\
p<0.001^{*}\end{array}$ & 0 & & $\begin{array}{c}65.7 \\
p<0.001^{*}\end{array}$ & 0 & & 10 \\
\hline $\begin{array}{l}\text { Proportion (\%) with negative Amsel's } \\
\text { criterion - } \\
\text { "release of fishy odor when alkali is added" }\end{array}$ & 8.1 & & $\begin{array}{c}70.6 \\
p<0.001^{*}\end{array}$ & 5.7 & & $\begin{array}{c}80 \\
p<0.001^{*}\end{array}$ & 8.2 & & 26.7 \\
\hline $\begin{array}{l}\text { Proportion (\%) with negative Amsel's } \\
\text { criterion - } \\
\text { "clue cells on microscopy" }\end{array}$ & 5.4 & & $\begin{array}{c}70.6 \\
p<0.001^{*}\end{array}$ & 8.6 & & $\begin{array}{c}85.7 \\
p<0.001^{*}\end{array}$ & 6.1 & & 6.7 \\
\hline $\begin{array}{l}\text { Proportion }(\%) \text { with negative Amsel's } \\
\text { criterion - } \\
\text { "pH of vaginal discharge } \leq 4.5 \text { " }\end{array}$ & 0 & & $\begin{array}{c}32.4 \\
p<0.05^{*}\end{array}$ & 0 & & $\begin{array}{c}37.1 \\
p<0.05^{*}\end{array}$ & 9.1 & & 10 \\
\hline $\begin{array}{l}\text { Statistical comparison of mean vaginal } \mathrm{pH} \\
\text { vs. Visit } 1 \text { (Wilcoxon signed rank test) }\end{array}$ & & $p<0.001$ & $p<0.05$ & & $p<0.001$ & $p=0.001$ & & $p<0.05$ & NS \\
\hline
\end{tabular}


- Page 6 of 12 -

\begin{tabular}{|c|c|c|c|c|c|c|c|c|c|}
\hline $\begin{array}{l}\text { Statistical comparison of mean vaginal } \mathrm{pH} \\
\text { change from Visit } 1 \text { vs. the control group } \\
\text { (Chi-square test) }\end{array}$ & & $p<0.001$ & NS & & $p<0.001$ & NS & & & \\
\hline Median vaginal $\mathrm{pH}$ & 5.4 & 4.3 & 5 & 5.2 & 4.4 & 4.7 & 5.4 & 5.2 & 5.3 \\
\hline $\begin{array}{l}\text { Proportion (\%) of patients with median } \\
\text { vaginal } \\
\mathrm{pH} \leq 4.5\end{array}$ & 2.7 & 69.4 & 38.2 & 2.9 & 60 & 37.1 & 12.1 & 13.3 & 16.7 \\
\hline $\begin{array}{l}\text { Proportion (\%) with a normal vulvovaginal } \\
\text { mucosa status at examination }\end{array}$ & 89.2 & & 88.2 & 88.6 & & 82.9 & 93.9 & & 90 \\
\hline $\begin{array}{l}\text { Total number and proportion (\%) of treated } \\
\text { patients reporting AEs }\end{array}$ & \multicolumn{3}{|c|}{$10(27)$} & \multicolumn{3}{|c|}{$13(31)$} & & & \\
\hline Total number of AEs/ADEs & \multicolumn{3}{|c|}{$23 / 17$} & \multicolumn{3}{|c|}{$25 / 19$} & & & \\
\hline \multirow[t]{2}{*}{ Proportion of ADEs considered as mild } & \multicolumn{3}{|c|}{$11 / 17$} & \multicolumn{3}{|c|}{$12 / 19$} & & & \\
\hline & Major & Slight & No & Major & Slight & No & & & \\
\hline $\begin{array}{l}\text { Investigator assessment of improvement at } \\
\text { final visit; proportion (\%) }\end{array}$ & 57 & 28 & 16 & 57 & 26 & 15 & & & \\
\hline
\end{tabular}

Table 4: Baseline data and treatment outcome in study Part B.

*versus CG (Chi-square test)

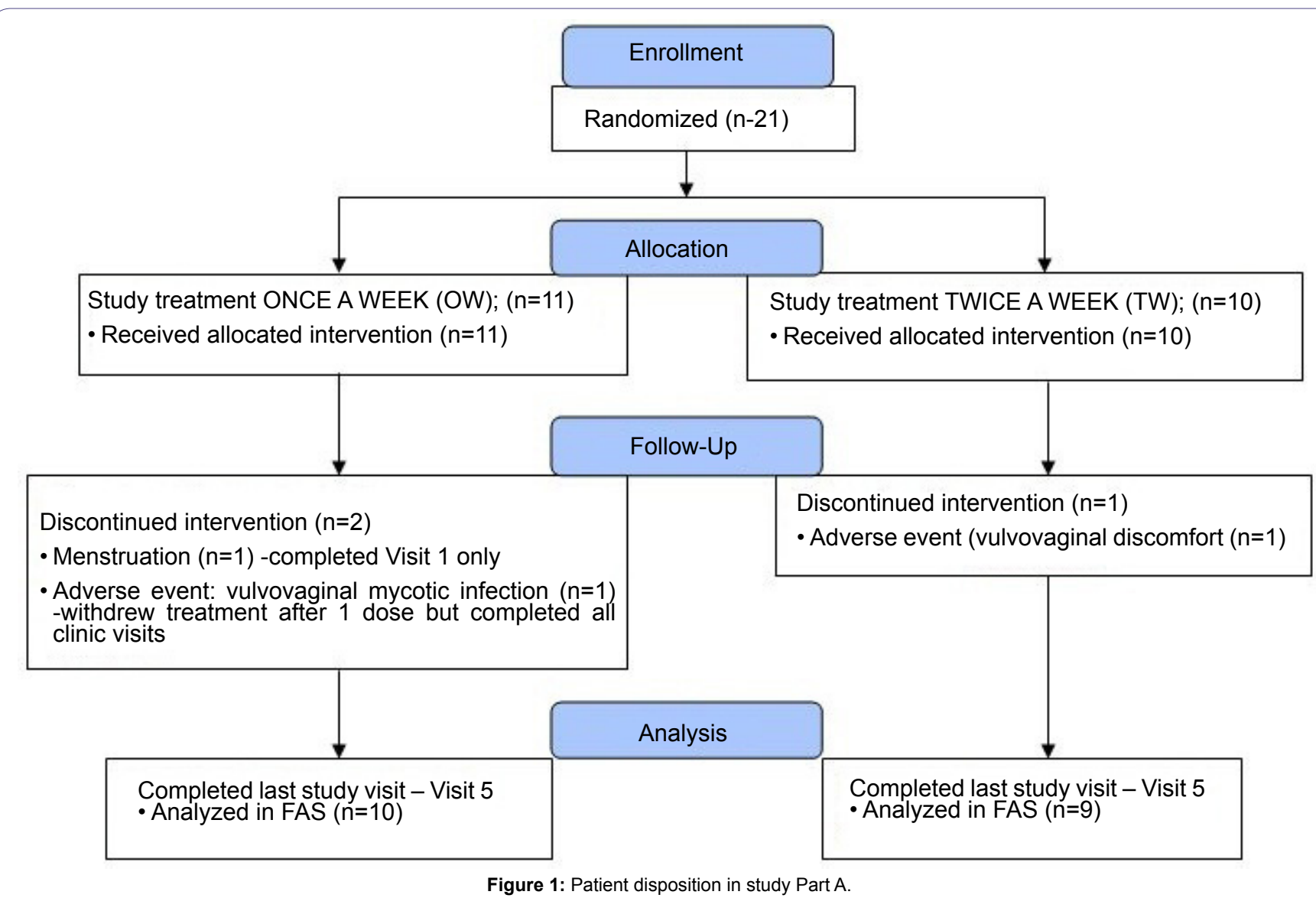

The number of patients with minor protocol deviations was 5 in the OW group and 6 in the TW group. The deviations related to the timing of the study visit windows and the timing of the recommended dosing schedule.

Baseline data from the two study parts is presented in tables 3 and 4 together with the treatment outcome. The demography and baseline data were similar between the groups in both parts of the study.

\section{Study part A}

Part A consisted of 21 eligible patients with confirmed diagnosis of BV randomized to treatment during the period March to October 2011. The patient disposition from Part A is presented in figure 1. The treatment outcome from study Part A is shown in table 3.
BV according to Amsel's criteria: Very high treatment efficacy was demonstrated in both groups for all efficacy endpoints. Convincing improvement rates were already observed after one week. The patient ratios with no BV (according to Amsel's criteria) were 10/10 in the OW group and $9 / 10$ in the TW group. After the second treatment week, the corresponding rates were $8 / 10$ in the OW group and 9/9 in the TW group.

Vaginal pH: The mean absolute vaginal $\mathrm{pH}$ was significantly reduced $(p<0.05)$ compared to the baseline in both groups at Visit 2 . The 
proportion of patients with median vaginal $\mathrm{pH}$ of $\leq 4.5$ increased from 0 at commencement of the study to $9 / 19$ (47\%) at Visit 2 (day 4). Later on in the study, the effect on $\mathrm{pH}$ was less pronounced in the OW group. After two weeks, the corresponding proportions were $1 / 10$ (10\%) in the OW group and 4/9 (44\%) in the TW group.

AEs and vulvovaginal mucosa examination: As expected, no Serious Adverse Events (SAEs) occurred. The majority of events reported were of mild intensity and short duration. Two patients, one patient in each group, were withdrawn from treatment due to an AE considered by the investigator to possibly be treatment related (i.e., an Adverse Drug Event (ADE)). The most common ADEs were vaginal itching and/or vaginal burning experienced by a total of 10 patients. No differences were seen between the groups.

A higher proportion of patients had a normal vulvovaginal mucosa appearance at the end of the study (84\%) compared to at inclusion (57\%), which shows that the treatment had no visually detectable negative impact on the mucosa.

Patient questionnaire and investigator assessment: The answers to the questionnaire showed that all patients completely or partly agreed that the OMLA pessary treatment was user-friendly, i.e., easy to insert, not messy to use, and comfortable. Furthermore, all patients agreed that it was convenient not to dose more often than once or twice a week.
According to the investigator assessments, $14 / 19$ (74\%) of treated patients were considered to have achieved major improvements from the treatment.

Overall results of part A: This study part confirmed not only the efficacy, safety and user-friendliness of the treatment, but also the $\mathrm{pH}$-lowering mechanism of action. However, due to the small number of patients, no conclusions regarding potential differences between the treatment schedules could be drawn. As the OMLA pessary performed as expected, the Proof of Concept was collected.

The results obtained in Part A were used in the final design of study Part $B$. As both treatment regimens were shown to be highly effective, the decision was made to continue with both regimens in Part B, but for only one week, as this seemed to be adequate time for studying the immediate treatment effects.

\section{Study part B}

In Part B, 105 eligible patients with confirmed diagnosis of BV were randomized into three study groups during the period January to June 2012. The patient disposition of study Part B is shown in figure 2 and the treatment outcome in table 4 . In the outcome presentation below, only the results related to the Full Analysis Set (FAS) are presented as the PP Analysis Set did not reveal any significant differences compared to the FAS. However, a trend towards better treatment effects in the PP population was seen.

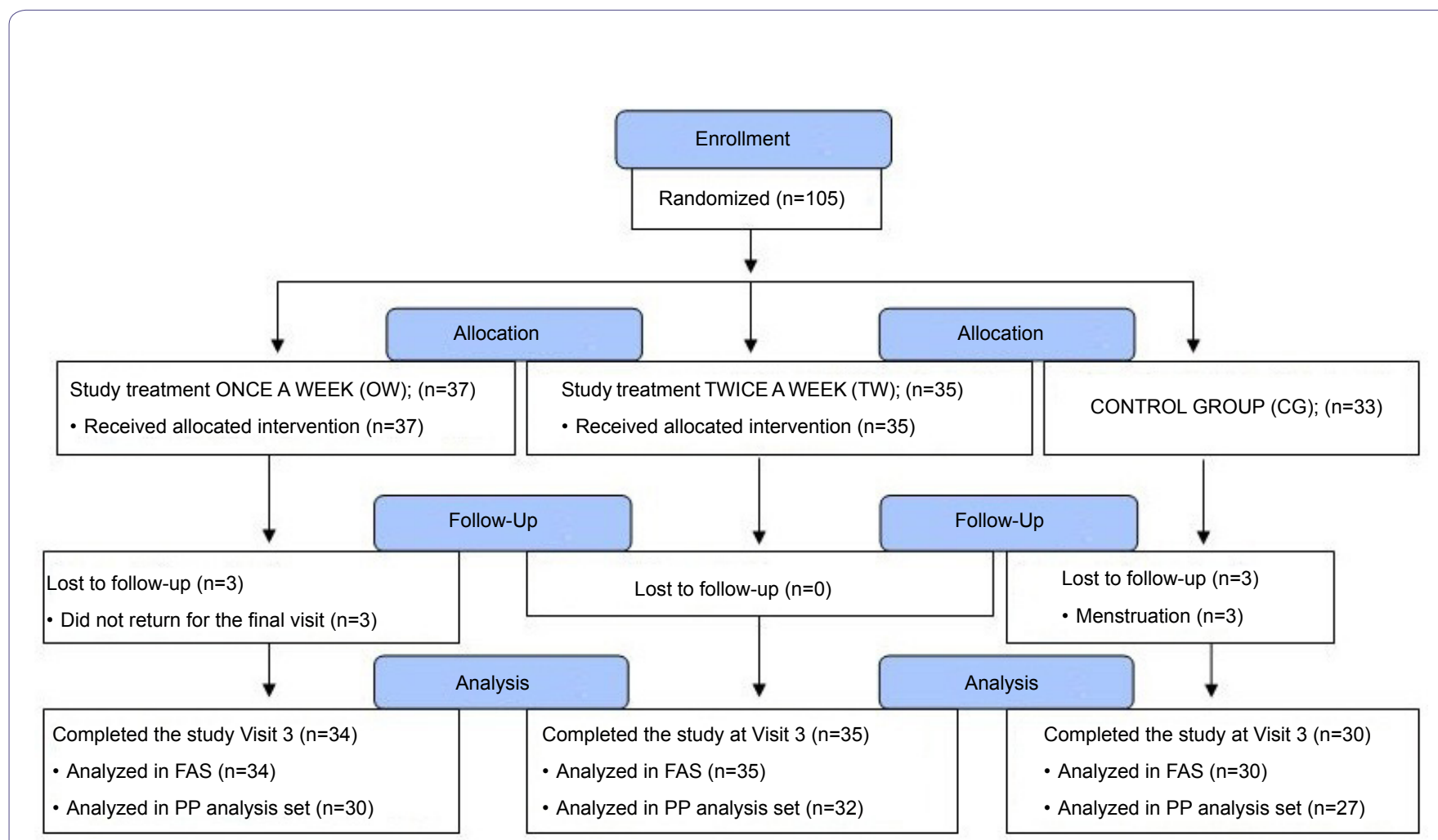

Figure 2: Patient disposition in study Part B.

The number of patients with minor protocol deviations was 7 in the OW group, 3 in the TW group and 6 in the CG. These patients were not included in the PP analysis set. The deviations in the three groups related to: missed study Visit 3 , menstruation, incorrect number of pessaries, incorrect pH assessment, and incorrect inclusion (post-menopausal). 
BV according to Amsel's criteria: A substantial change in terms of no BV was seen in the OW and the TW groups, but not in the CG. The primary comparison of treatment efficacy, the proportion of patients with no BV after one week, was $70.6 \%$ in the OW group and $10.0 \%{ }^{2}$ in the CG. This association between treatment and response was highly significant $(p<0.001)$. The proportion of patients with no BV in the TW group was $80.0 \%(p<0.0001$ vs. CG). There was, however, no statistically significant association in the response between the two treated groups.

The control patients who still had verified BV after the first week of non-treatment were offered treatment with the OMLA pessary during week 2 . When the results from the second week were added, the corresponding results for the OW group were $74.0 \%$ and $75.0 \%$ for the TW group.

For all four Amsel's criteria, the differences in response rates were statistically significant in favor of each of the treatment groups versus the CG.

Vaginal pH: Compared to baseline, the mean $\mathrm{pH}$ value within the OW group was reduced 1.0 unit at day 4 and 0.5 units at day $8(\mathrm{p}<0.01$ and $\mathrm{p}<0.05$, respectively). The corresponding $\mathrm{pH}$ changes within the TW group and the CG were 0.9 and 0.7 units and 0.1 and 0.1 units, respectively (TW $\mathrm{p}<0.001$ and $\mathrm{p}=0.001$; CG $\mathrm{p}<0.05$, NS) (Table 4).

AEs and vulvovaginal mucosa examination: None of the reported AEs or ADEs with a possible relationship to the treatment was deemed serious and no patient withdrew from treatment due to an AE. Approximately $30 \%$ of the patients reported at least one AE. The majority (64\%) of the ADEs were of mild intensity and normally of short duration. Two patients were diagnosed with a yeast infection.

The most common ADE was vaginal itching reported by 5 patients in the OW group and by 6 patients in the TW group. Other events, reported by more than one subject per group, were vaginal irritation and a genital burning sensation. No clear differences in relation to AEs were seen between the treatment groups.

The majority of the patients had a normal vulvovaginal mucosa status at baseline and at the end of the treatment.

Patient questionnaire and investigator assessment: More than $85 \%$ completely agreed with the statement that the OMLA pessary treatment was user-friendly, as it was easy to insert, not messy to use and comfortable. More than $80 \%$ completely agreed that it was convenient not have to dose more often. There were no significant differences between the treatment groups in relation to any of the questions. The results verified a high treatment satisfaction and acceptance of the OMLA pessary.

According to the investigator assessments, the clinical outcome of the OMLA pessary treatment was judged as improved (major or slight) compared to baseline for over $83 \%$ of the treated patients.

Overall results of part B: Both treatment schedules of the OMLA pessary were shown to be highly effective. The results also confirmed the safety and user-friendliness of the treatment. No clear differences between the treatment schedules were observed.

\section{Consolidated results from parts $A$ and $B$}

The results from study Part A regarding proportion of patients with no BV after one week of treatment were combined with the corresponding results from Part B (Figure 3). This consolidation showed a treatment success ratio of $47 / 60(78.3 \%)$ in the OW group, $42 / 54(77.8 \%)$ in the TW group, and $89 / 114(78.1 \%)$ in the pooled group with all treated patients, including the patients who were treated during week 2, after first participating in the CG during week 1 .

The results from study Part A regarding vaginal $\mathrm{pH}$ at baseline, Visit 2, and Visit 3 were also combined with the corresponding results in Part B. The outcome from the pooled treatment groups with all treated patients showed median reductions of approximately 0.9 units and 0.4 units at Visit 2 and Visit 3, respectively (Figure 4).

\section{Discussion}

Some of the widely-used regimens for the treatment of symptomatic BV are comprised of antibiotics. The use of antibiotics is not only associated with a risk for bacterial drug resistance development, but may, for some antibiotics commonly used for BV, also involve potential interactions with alcohol or drugs and the risk of a wide range of adverse events of which Candida vaginitis is very common [28,29].

Cure rates not exceeding $60-70 \%$ four weeks after oral or topical antibiotic treatments and relapse rates of approximately $70 \%$ in long-term follow-up studies ( $>4$ weeks after treatment) reported in a review have led to the conclusion that no sound scientific basis yet exists for recommending any particular therapeutic treatment for BV [37].

The dominance of Lactobacilli in healthy vaginal microbiota and its depletion due to BV has given rise to the concept of oral or vaginal use of probiotic Lactobacillus strains for the prevention of BV. However, sufficient evidence for recommending probiotics for the treatment of BV is still lacking [38]. Increase of vaginal pH leads to the decrease of the Lactobacilli-associated antimicrobial activity which may explain the lack of efficacy in patients with established BV [4-5].

These results render the search for new efficacious therapeutic agents for BV even more important.

\section{Main findings}

Treatment with the OMLA pessary resulted in pronounced positive effects on the BV healing rate, which was $78 \%$ with both treatment schedules already after one week and a single-dose administration, using the Amsel's criteria. A pronounced positive effect was also seen for the Amsel's criteria related to clue cells, discharge, and vaginal odor, but the effect on $\mathrm{pH}$ was lower. The mean change in vaginal $\mathrm{pH}$ of $0.5-1.0 \mathrm{pH}$ units towards physiological levels obtained with the OMLA pessary seems to be sufficient to induce restoration of a healthy vaginal microbiological ecosystem and to cure or improve the symptoms of BV. Although a lactobacilli count was not performed in this study, it is reasonable to believe that the rapid symptom improvements seen during treatment with the pessary are correlated to the reappearance of a Lactobacilli-dominated vaginal flora. This was seen in a study where a lactic acid gel for topical administration was used daily for seven days either alone or in combination with oral metronidazole [39]. In that study, the vaginal $\mathrm{pH}$ changes approaching the range seen in our study were also measured during treatment and seven days after completed treatment.

2 - Including one patient by mistake treated by active treatment from Visit 2 and at Visit 3 was assessed as having no BV 


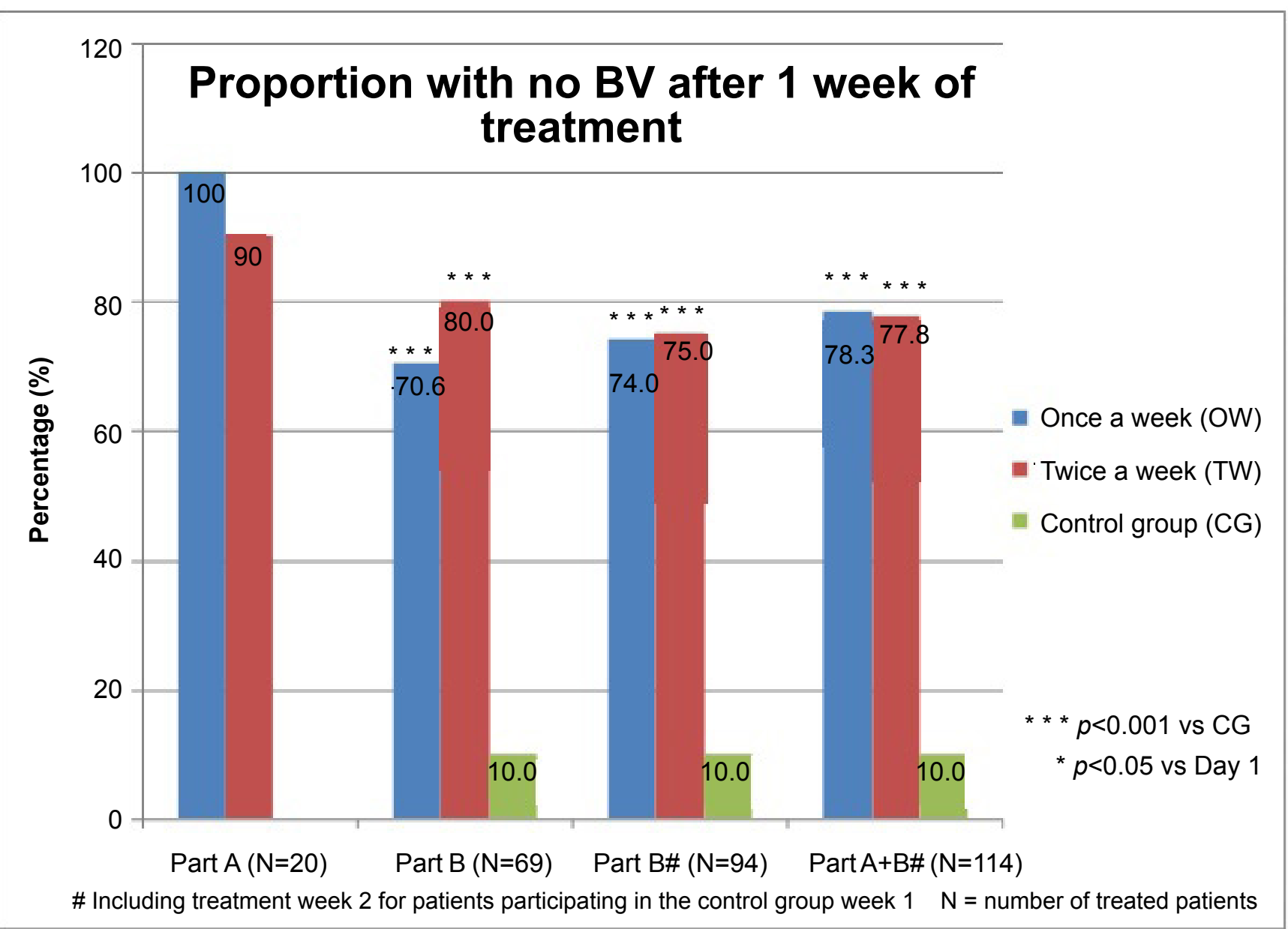

Figure 3: Proportion of treatment successes separately and combined.

The vaginal $\mathrm{pH}$ in healthy women is reported to be 4.0-4.5 [40]. Based on the study results, it can be speculated that women frequently suffering from BV, compared to women never developing BV, have a higher "normal" $\mathrm{pH}$ range, which would increase the susceptibility for BV development.

The mechanism of action for the OMLA pessary is its $\mathrm{pH}$-lowering effect, so it may seem somewhat contradictory that among the four Amsel's criteria, the effect on $\mathrm{pH}$ was the least pronounced. However, if the theory presented is correct, the $\mathrm{pH}$ limit of 4.5 in Amsel's criteria should be somewhat higher. There are reports in literature where a $\mathrm{pH}$ of 4.7 has been used instead $[34,39,41]$. In the study by Decena et al., with 30 patients in each of three treatment groups (lactic acid gel, oral metronidazole or lactic acid gel combined with oral metronidazole), there was only a slight $\mathrm{pH}$ decrease of 0.4 units and a mean $\mathrm{pH}$ of 4.8 in the group with the combined treatment which reported the most pronounced $\mathrm{pH}$ effect [39]. Less than $50 \%$ of the patients in this group received a $\mathrm{pH}$ below 4.7. Despite this moderate $\mathrm{pH}$ decrease there were positive effects on the other Amsel's criteria, which also was the case when patients were treated with lactic acid gel alone.

No alarming events were reported concerning the OMLA pessary in this study. The most frequently reported event was vaginal itching which was mentioned by less than $20 \%$ of the participants. Only two patients were reported to have contracted a yeast infection, which is a commonly reported problem after treatment with antibiotics $[28,29,38]$. The events were generally of short duration and mild intensity and were not a reason for withdrawal from treatment or the study. Furthermore, the vulvovaginal examinations verified that the treatment had no visually detected negative impacts on the mucosa.

\section{Strengths and limitations}

Despite the fact that BV is rated as one of the most frequent vaginal infections and is associated with medically important complications and huge discomfort to those affected, there is at present no treatment option that is not only efficacious and safe, but also has documented patient-friendly characteristics and is well accepted [13]. The results from this study, based on clinical data from 126 patients with confirmed BV treated for one or two weeks, clearly show that the OMLA pessary in treatment regimens with administrations once or twice a week is not only highly effective, safe, and well tolerated, but also considered highly user-friendly by the treated women. These strengths in the product characteristics of the OMLA pessary display properties suitable for an OTC product aimed for self-medication when symptoms of BV occur.

Recurrence of symptoms is common among women suffering from BV. With this new OMLA pessary, recurrences are easily and conveniently treated with only one pessary administration. For patients with frequent recurrences, the pessary would be especially appropriate since antibiotics should be restrictively used [27]. 


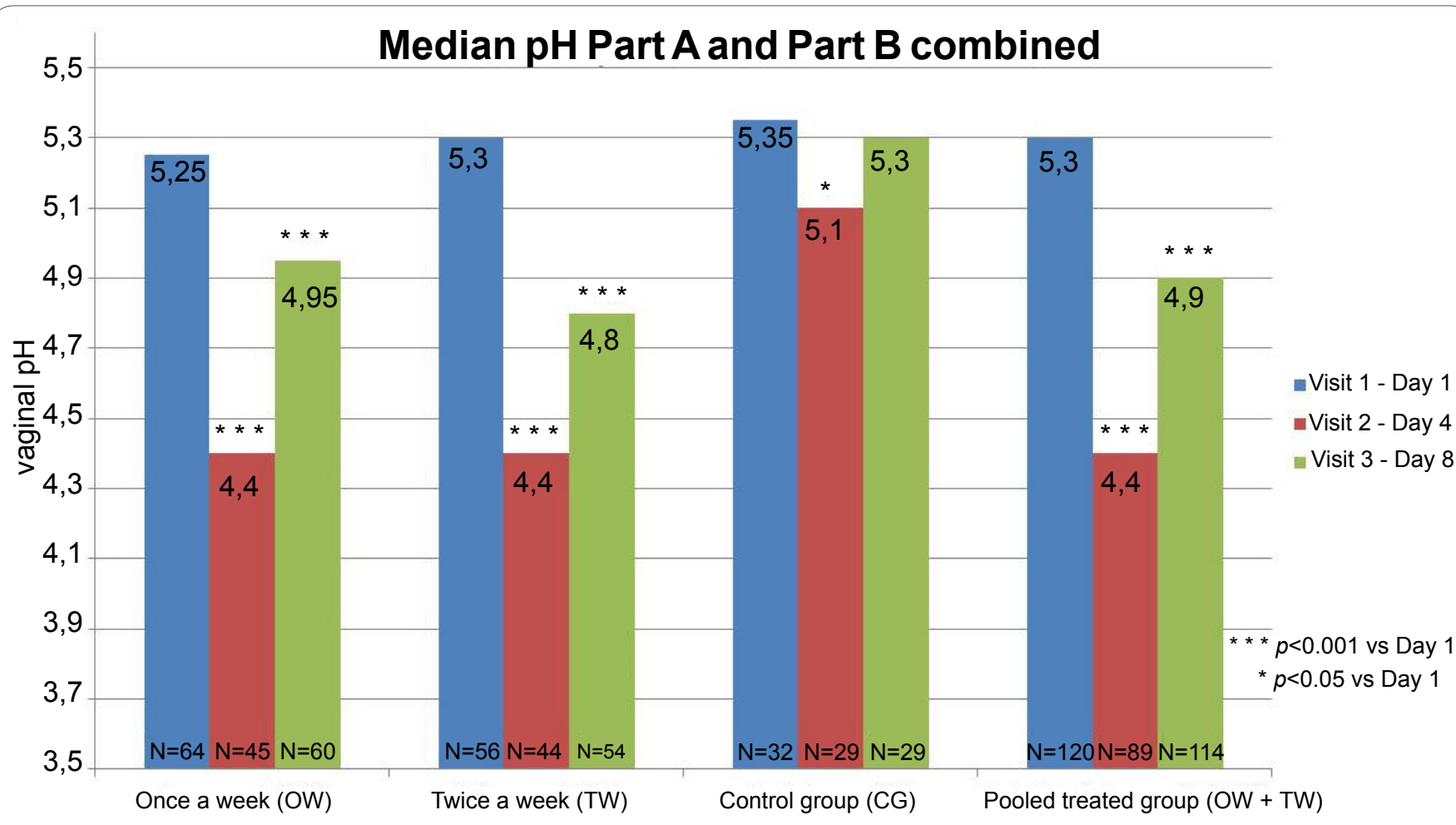

Figure 4: Median vaginal $\mathrm{pH}$ at Visits 1-3 when Part $\mathrm{A}$ and Part $\mathrm{B}$ are combined

Furthermore, the current study focused on the immediate treatment effects of the OMLA pessary with no BV follow-up after completion of treatment. This approach was chosen as there is no generally accepted standard length of follow-up after treatment. Since the follow-up periods differ between studies the results are often not directly comparable. However, as no follow-up observations were done after completion of treatment, it is unclear whether the pessary will provide any sustained relief.

The limitation with a non-blinded study design may have biased the treatment outcomes in a way that AEs from actively treated patients would more easily be interpreted as treatment related compared to those from untreated patients.

According to a recently performed literature review BV should be diagnosed using either clinical (Amsel's) or laboratory (Gram stain with objective scoring system) criteria [42]. Amsel's criteria has been presented in section Methods [8]. For Amsel's criteria the sensitivity and positive predictive value are both $90 \%$ [43]. The Nugent Score is a Gram stain scoring system for pap tests to diagnose bacterial Vaginosis [9]. It was first described in 1991 by RP Nugent, whom it is named after [9]. The Nugent score is calculated by assessing for the presence of large Gram positive rods (Lactobacillus morphotypes; decrease in Lactobacillus scored as 0 to 4), small Gram-variable rods (Gardnerella vaginalis morphotypes; scored as 0 to 4 ), and curved Gram-variable rods (Mobiluncus spp. morphotypes; scored as 0 to 2) and can range from 0 to 10 . A score of 7 to 10 is consistent with bacterial Vaginosis [9]. Vaginal Gram stain is reliable and allows for permanent record. Cultures are nonspecific because Gardnerella vaginalis resides in normal vaginal flora as well [43].
Amsel's criteria and Nugent scoring system are among the most commonly used diagnostic methods of BV. Although Nugent scoring system is considered the gold standard for diagnosing BV, it is time consuming and costly, and its interpretation needs lab equipment and experts. Hence, most physicians are inclined to use simpler clinical criteria that are yet accurate instead [44]. In the current study it was thus decided to use Amsel's criteria as this method was also considered as logistically easier to use in a multicenter setting.

\section{Interpretation}

A major challenge with $\mathrm{BV}$ is the prevention of recurrence and the long-term cure. Treatment of BV using antibiotics is often associated with high rates of recurrence even after a proper treatment course which might reflect resistance, recurrence and/or reinfection and/or be a consequence of insufficient $\mathrm{pH}$ restoration $[7,45]$. Intermittent local prophylactic treatments with a lactic acid vaginal gel in women experiencing recurrent $\mathrm{BV}$ has been evaluated in a double-blind placebo controlled six month study [20]. That study verifies that a local vaginal lactic acid formulation can be used successfully not only for treatment of acute symptoms, but also prophylactically to restore a normal $\mathrm{pH}$ and microflora and to prevent recurrences [41].

Favorable effects of vaginal acidification for the prevention of recurrent BV have also been presented in a study of a commercial vaginal gel containing diluted buffered acetic acid. Here, the vaginal gel used was associated with a significant decrease in the number of women with relapses, as well as the recurrence rate [46].

The data reported in the literature support that the OMLA pessary should encompass qualities suitable not only for the acute treatment of BV symptoms but also for a prophylactic use to normalize an 
abnormal vaginal $\mathrm{pH}$ and microflora in order to prevent recurrences. To confirm the restoration of the normal Lactobacilli flora after treatment with the OMLA pessary a new clinical trial in women with BV should be undertaken using the Nugent score. In the same trial, prevention of BV recurrence using one OMLA pessary a month (after completed menstruation) for 4-6 months could also be studied.

\section{Conclusion}

The OMLA pessary, a novel treatment of BV, showed a treatment efficacy of $78 \%$ already after a week at a single-dose administration. Along with a good safety profile and by meeting patient's need of user-friendly comfort, with no risk of bacterial antibiotic resistance development, this represents a significant improvement in the treatment of BV.

\section{References}

1. Holmes KK, Spiegel C, Amsel AR, Eschenbach DA, Chen KC, et al. (1981) Nonspecific vaginosis. Scand J Infect Dis Suppl 26: 110-114.

2. Spiegel CA, Davick P, Totten PA, Chen KC, Eschenbach DA, et al. (1983) Gardnerella vaginalis and anaerobic bacteria in the etiology of bacterial (nonspecific) vaginosis. Scand J Infect Dis Suppl 40: 41-46

3. Hillier SL, Nugent RP, Eschenbach DA, Krohn MA, Gibbs RS, et al. (1995) Association between bacterial vaginosis and preterm delivery of a low-birthweight infant. The Vaginal Infections and Prematurity Study Group. N Engl J Med 333: 1737-1742.

4. Pybus V, Onderdonk AB (1999) Microbial interactions in the vaginal ecosystem, with emphasis on the pathogenesis of bacterial vaginosis. Microbes Infect 1: 285-292.

5. Valore EV, Wiley DJ, Ganz T (2006) Reversible deficiency of antimicrobial polypeptides in bacterial vaginosis. Infect Immun 74: 5693-5702.

6. Sobel JD (1990) Bacterial vaginosis. Br J Clin Pract Suppl 71: 65-69.

7. Verstraelen $H$, Verhelst $R$ (2009) Bacterial vaginosis: an update on diagnosis and treatment. Expert Rev Anti Infect Ther 7: 1109-1124.

8. Amsel R, Totten PA, Spiegel CA, Chen KC, Eschenbach D, et al. (1983) Nonspecific vaginitis. Diagnostic criteria and microbial and epidemiologic as sociations. Am J Med 74: 14-22.

9. Nugent RP, Krohn MA, Hillier SL (1991) Reliability of diagnosing bacteria vaginosis is improved by a standardized method of gram stain interpretation. J Clin Microbiol 29: 297-301.

10. Koumans EH, Sternberg M, Bruce C, McQuillan G, Kendrick J, et al. (2007) The prevalence of bacterial vaginosis in the United States, 2001-2004; associations with symptoms, sexual behaviors, and reproductive health. Sex Transm Dis 34: 864-869.

11. Holzman C, Leventhal JM, Qiu H, Jones NM, Wang J, et al. (2001) Factors linked to bacterial vaginosis in nonpregnant women. Am J Public Health 91 : 1664-1670.

12. Kenyon C, Colebunders R, Crucitti T (2013) The global epidemiology of bacterial vaginosis: a systematic review. Am J Obstet Gynecol 209: 505-523.

13. Fredstorp M (2015) Foul-smelling vaginal discharge, a hidden health problem at bacterial vaginosis; outcome from an international web-based survey in 2660 women in USA, UK and Germany. XXI FIGO World Congress in Gynecol \& Obstet, Vancouver, Canada.

14. Eschenbach DA (2004) Vaginitis, cervicitis and endometritis. In: Gorbach SL, Bartlett JG, Blacklow NR (eds.). Infectious diseases (3rdedn). Lippincott Williams \& Wilkins, Philadelphia, USA. Pg no: 947.

15. Joesoef MR, Schmid GP (1995) Bacterial vaginosis: review of treatment options and potential clinical indications for therapy. Clin Infect Dis 20: 72-79.
16. Flynn CA, Helwig AL, Meurer LN (1999) Bacterial vaginosis in pregnancy and the risk of prematurity: a meta-analysis. J Fam Pract 48: 885-892.

17. Leitich H, Bodner-Adler B, Brunbauer M, Kaider A, Egarter C, et al. (2003) Bacterial vaginosis as a risk factor for preterm delivery: a meta-analysis. Am J Obstet Gynecol 189: 139-147.

18. Hay PE (2004) Bacterial vaginosis and miscarriage. Curr Opin Infect Dis 17 : 41-44.

19. Schwebke JR, Desmond R (2005) Risk factors for bacterial vaginosis in women at high risk for sexually transmitted diseases. Sex Transm Dis 32: 654-658.

20. Hay PE, Morgan DJ, Ison CA, Bhide SA, Romney M, et al. (1994) A longitudinal study of bacterial vaginosis during pregnancy. Br J Obstet Gynaecol 101: 1048-1053.

21. Svare JA, Schmidt H, Hansen BB, Lose $G$ (2006) Bacterial vaginosis in a cohort of Danish pregnant women: prevalence and relationship with preterm delivery, low birthweight and perinatal infections. BJOG 113: 1419-1425.

22. Right diagnosis (2008) Bacterial Vaginosis. Statistics about Bacterial Vaginosis. Right Diagnosis, USA.

23. Schmid G, Markowitz L, Joesoef R, Koumans E (2000) Bacterial vaginosis and HIV infection. Sex Transm Infect 76: 3-4.

24. Smart S, Singal A, Mindel A (2004) Social and sexual risk factors for bacterial vaginosis. Sex Transm Infect 80: 58-62.

25. Li XD, Wang CC, Zhang XJ, Gao GP, Tong F, et al. (2014) Risk factors for bacterial vaginosis: results from a cross-sectional study having a sample of 53,652 women. Eur J Clin Microbiol Infect Dis 33: 1525-1532.

26. CDC (2015) 2015 Sexual Transmitted Diseases Treatment Guidelines. Center for Disease Control and Prevention, US Department of Health and Human Services, USA.

27. Laxminarayan R, Duse A, Wattal C, Zaidi AK, Wertheim HF, et al. (2013) Antibiotic resistance-the need for global solutions. Lancet Infect Dis 13: 10571098.

28. Bluestein D, Rutledge C, Lumsden L (1991) Predicting the occurrence of Antibiotic-induced Candidal Vaginitis (AICV). Fam Pract Res J 11: 319-326.

29. Pirotta MV, Gunn JM, Chondros P (2003) "Not thrush again!” Women's experience of post-antibiotic vulvovaginitis. Med J Aust 179: 43-46.

30. Martinez V, Caumes E (2001) [Metronidazole]. Ann Dermatol Venereol 128: 903-909.

31. Aroutcheva A, Simoes JA, Shott S, Faro S (2001) The inhibitory effect of clindamycin on Lactobacillus in vitro. Infect Dis Obstet Gynecol 9: 239-244.

32. Simoes J, Aroutcheva A, Shott S, Faro S (2001) Effect of metronidazole on the growth of vaginal Lactobacilli in vitro. Infect Dis Obstet Gynecol 9: 41-45.

33. Dover SE, Aroutcheva AA, Faro S, Chikindas ML (2008) NATURAL ANTIMICROBIALS AND THEIR ROLE IN VAGINAL HEALTH: A SHORT REVIEW. Int J Probiotics Prebiotics 3: 219-230.

34. Holst E, Brandberg A (1990) Treatment of bacterial vaginosis in pregnancy with a lactate gel. Scand J Infect Dis 22: 625-626.

35. Petersen EE, Genet M, Caserini M, Palmieri R (2011) Efficacy of vitamin C vaginal tablets in the treatment of bacterial vaginosis: a randomised, double blind, placebo controlled clinical trial. Arzneimittelforschung 61: 260-265.

36. ICH (1998) ICH Harmonised Tripartite Guideline, Guideline For Good Clinical Practice E6(R1). International conference on harmonization of technical requirements for registration of pharmaceuticals for human use. $\mathrm{ICH}$, Geneva, Switzerland.

37. Larsson PG, Forsum U (2005) Bacterial vaginosis--a disturbed bacterial flora and treatment enigma. APMIS 113: 305-316.

38. Mastromarino P, Vitali B, Mosca L (2013) Bacterial vaginosis: a review on clinical trials with probiotics. New Microbiol 36: 229-238. 
39. Decena DC, Co JT, Manalastas RM Jr, Palaypayon EP, Padolina CS, et al. (2006) Metronidazole with Lactacyd vaginal gel in bacterial vaginosis. J Obstet Gynaecol Res 32: 243-251.

40. Melis GB, Ibba MT, Steri B, Kotsonis P, Matta V, et al. (2000) [Role of pH as a regulator of vaginal physiological environment]. Minerva Ginecol 52: 111-121.

41. Andersch B, Lindell D, Dahlén I, Brandberg A (1990) Bacterial vaginosis and the effect of intermittent prophylactic treatment with an acid lactate gel. Gynecol Obstet Invest 30: 114-119.

42. van Schalkwyk J, Yudin MH, Allen V, Bouchard C, Boucher M, et al. (2015) Vulvovaginitis: screening for and management of trichomoniasis, vulvovaginal candidiasis, and bacterial vaginosis. J Obstet Gynaecol Can 37: 266-276.
43. Mohammadzadeh F, Dolatian M, Jorjani M, Alavi Majd H (2014) Diagnostic value of Amsel's clinical criteria for diagnosis of bacterial vaginosis. Glob J Health Sci 7: 8-14.

44. Eschenbach DA (2007) Bacterial vaginosis: resistance, recurrence, and/or reinfection? Clin Infect Dis 44: 220-221.

45. Wilson JD, Shann SM, Brady SK, Mammen-Tobin AG, Evans AL, et al. (2005) Recurrent bacterial vaginosis: the use of maintenance acidic vaginal gel following treatment. Int J STD AIDS 16: 736-738.

46. Wang J (2000) Bacterial vaginosis. Prim Care Update Ob Gyns 7: 181-185 